\title{
Relationship of Serum Pentraxin-3 with Peripheral Arterial Disease
}

Burak Katipoglu', Ali Aygun'2, Selim Demir ${ }^{3}$, Ozgur Tatli, Ahmet Mentese ${ }^{5}$, Umit Mentese ${ }^{6}$, Gokalp Altun ${ }^{7}$, Asim Orem ${ }^{8}$, Abdulkadir Gunduz ${ }^{4}$, Semih Korkut ${ }^{9}$, Togay Evrin ${ }^{10}$

'Department of Emergency Medicine, Ankara Training and Research Hospital, Ankara, Turkey

2Department of Emergency Medicine, Ordu University Training and Research Hospital, Ordu, Turkey

${ }^{3}$ Department of Nutrition and Dietetics, Karadeniz Technical University School of Medicine, Trabzon, Turkey

${ }^{4}$ Department of Emergency Medicine, Karadeniz Technical University School of Medicine, Trabzon, Turkey

${ }^{5}$ Program of Medical Laboratory Techniques, Karadeniz Technical University Vocational School of Medicine, Trabzon, Turkey

${ }^{6}$ Department of Cardiovascular Surgery, Ahi Evren Thoracic and Cardiovascular Surgery Training and Research Hospital, Trabzon, Turkey

${ }^{7}$ Department of Cardiovascular Surgery, Karadeniz Technical University School of Medicine, Trabzon, Turkey

${ }^{8}$ Department of Medical Biochemistry, Karadeniz Technical University School of Medicine, Trabzon, Turkey

${ }^{9}$ Public Hospitals Association Bakırkoy General Secretaria, İstanbul, Turkey

${ }^{10}$ Department of Emergency Medicine, Ufuk University School of Medicine, Dr. Ridvan Ege Training and Research Hospital, Ankara, Turkey

Cite this article as: Katipoglu B, Aygun A, Demir S, Tatli O, Mentese A, Mentese U, et al. Relationship of Serum Pentraxin-3 with Peripheral Arterial Disease. Eurasian J Emerg Med. 2018; 17 (4): 187-92.

\begin{abstract}
Aim: Atherosclerosis is a chronic inflammatory process associated with peripheral artery disease (PAD). The aim of this study was to investigate the role of pentraxin (PTX) as an inflammatory marker in the pathogenesis of PAD.

Materials and Methods: This cross-sectional clinical study was performed at the tertiary university hospital emergency department and cardiovascular surgery departments in Turkey. The purpose was to determine the value of PTX 3 in the diagnosis of PAD. This study was performed on 43 symptomatic patients aged $>18$ years and diagnosed with PAD.

Results: Median PTX3 value was 1.027 (25-75 th percentile: $0.395-2.902)$ in the control group and 0.585 (25-75 $5^{\text {th }}$ percentiles: $\left.0.406-5.467\right)$ in the PAD group $(p=0.913)$. A comparison of PTX3 with ankle brachial index (ABI) values revealed a weak and non-significant correlation (rho: $0.016, p=0.886)$. Analysis of PTX3 values with other parameters (age, systolic and diastolic blood pressure, heart rate, respiratory rate, temperature, and $\mathrm{SpO}_{2}$ ) revealed no significant correlation with any of the other parameters.
\end{abstract}

Conclusion: Our findings indicate that PTX3 levels cannot be used as a marker in patients with the chronic process of PAD.

Keywords: Atherosclerosis, inflammation, pentraxin-3, peripheral arterial disease

\section{Introduction}

Peripheral artery disease (PAD) is a widely occurring condition. The main cause is atherosclerosis, and the causes of atherosclerosis constitute the predisposing factors for the disease (1).
Atherosclerosis, the cause of PAD, is generally a condition of advanced age. It develops in association with intimal plaques affecting arterial circulation of the vascular system and containing varying proportions of lipids, macrophages, fibroblasts, smooth muscle cells, and extracellular materials. Atherosclerosis is also a chronic inflammatory condition (2).

\section{Corresponding Author: Ali Aygun e-mail: dr_aliaygun@hotmail.com}


Pentraxins (PTX) are multifunctional protein superfamily that play a role in the inflammatory response. PTX3 is one of the main acute phase reactants, which may increase in circulation 3-5 times above the baseline in inflammatory conditions. PTX3 is produced in the region of inflammation and binds immediately to the endothelium. PTX3 levels are believed to be an independent marker of disease activity (3).

Since a chronic inflammatory process is involved in atherosclerosis, PTX3 is an inflammatory marker that might be expected to increase in PAD. This study investigated whether PTX3 increases in patients with PAD.

\section{Materials and Methods}

Patients with suspected PAD based on symptoms at presentation to the tertiary university hospital emergency department and cardiovascular surgery departments over a 12-month period were included in this cross-sectional clinical study after receiving of approval from the local ethics committee. The study enrolled 43 consecutive adult patients presenting to the aforementioned units with suspected PAD and 40 age- and sex-matched healthy controls contacted from outside the hospital.

Patients aged $\geq 18$ years presenting to the departments with suspected PAD and agreeing to participate were included. Exclusion criteria were patients with acute coronary syndrome, acute kidney failure, chronic kidney failure, hemorrhagic stroke, cerebrovascular disease, liver failure, acute pulmonary edema, cardiopulmonary arrest, acute mesenteric ischemia, or pulmonary thromboembolism.

Clinical and demographic characteristics, such as symptoms, physical examination findings and Doppler ultrasound, peripheral arterial with contrast computerized tomography, and magnetic resonance angiography details were recorded into a study form.

The control group inclusion criteria included non-pregnant or puerperant patients, aged $\geq 18$ years with no acute kidney failure, chronic kidney failure, sepsis, ischemic stroke, liver failure, acute pulmonary edema, PAD, deep vein thrombosis, acute coronary syndrome, pulmonary embolism, mesenteric ischemia, cardiopulmonary arrest, multi-trauma, Tissue Plasminogen Activator (TPA)-related hemorrhage or acute trauma.

For PTX3 measurements at the time of presentation, a complete blood count $(\mathrm{CBC})$ was performed by collecting blood samples in the anticoagulant ethylenediaminetetraacetic acid (EDTA) tubes. Plasma was separated by centrifugation at $1800 \times \mathrm{g}$ for $10 \mathrm{~min}$ and then stored at $-80^{\circ} \mathrm{C}$ until PTX3 study.

\section{Measurement of plasma pentraxin-3}

PTX-3 levels in human plasma were determined using a commercial enzyme-linked immuno-sorbent assay (ELISA) kit (R\&D Systems, Cat No: DPTX30, Minneapolis, USA) following the manufacturer's instructions. Plasma stored at $-80^{\circ} \mathrm{C}$ was thawed to room temperature.
Briefly, $200 \mu \mathrm{L}$ of PTX3 biotinylated antibody was added into each well of a streptavidin-coated plate. Plates were incubated for 60 min at room temperature on a microplate shaker. The plates were subsequently washed using $300 \mu \mathrm{L}$ washing buffer to remove nonbinding antibodies. PTX3 standards were prepared in line with the kit procedures. Standards, controls, and specimens were activated with pre-treatment $D$ solution for $30 \mathrm{~min}$. Further, $100 \mu \mathrm{L}$ assay diluent solution was added to each plate; $20 \mu \mathrm{L}$ of pre-treated standards, controls, and specimens were added to the solution and incubated for $120 \mathrm{~min}$ in a microplate shaker at room temperature. Following incubation, the plate was washed four times with washing buffer in a plate washer; $200 \mu \mathrm{L}$ of PTX3 conjugate was added into the wells and incubated at room temperature for $120 \mathrm{~min}$ on a microplate shaker. Following incubation, the plate was washed four times using washing buffer in a plate washer. Subsequently, $200 \mu \mathrm{L}$ of Tetra Metil Benzidin (TMB) substrate solution was added to each well for color development and incubated in dark for 30 min at room temperature; $50 \mu \mathrm{L}$ of color stop solution was added to each well, and specimens were observed to turn yellow in color. Absorbance was measured at a wavelength of $450 \mathrm{~nm}$ using a microplate reader (Versamax, Molecular Devices, CA, USA). A standard chart was prepared using the absorbance values against standard concentrations obtained. PTX3 levels in specimens were calculated as $\mathrm{ng} / \mathrm{mL}$ using this standard chart. The intra-assay distribution reliability of this ELISA method was $3.6 \%$ and the inter-assay distribution reliability was $4.9 \%$.

\section{Statistical analysis}

Statistical analyses were performed using the Statistical Package for Social Sciences (SPSS Inc.; Chicago, IL, USA) version 11 software. The normality of the distribution of variables was tested using visual (histogram and probability charts) and analytical methods (Kolmogorov-Smirnov/Shapiro-Wilk tests). Descriptive analyses were expressed as mean and standard deviation for normally distributed variables. These were compared on $2 \times 2$ grids using Person's chi square and Fisher's exact tests. Since PTX 3 and ankle brachial index $(\mathrm{ABI})$ values were not normally distributed, these were analyzed using the Mann-Whitney $U$ test between two groups and with the KruskalWallis test between more than two groups. Spearman's correlation test was used to investigate correlations. $P$ values less than 0.05 were regarded as statistically significant.

\section{Results}

The mean age of the participants was $63.9 \pm 11.9$ years (min: 40 , max: 86 ) in the control group and $64.5 \pm 13.8$ years (min: 21 , max: 88 ) in the patient group. Males comprised $67.5 \%$ of the control group and $81.4 \%$ of the patient group. No significant difference was observed between the two groups in terms of age or gender distribution ( $p>0.05 ;$ Table 1$)$

When physical examination findings were compared between the control and patient groups, no ulcer, muscular atrophy, claudication, rash, or edema were observed in the control group; however, ulcer was present in $41.9 \%$, muscular atrophy in $9.3 \%$, claudication in $100 \%$, rash in $53.5 \%$, and edema in $44.2 \%$ of the patient group ( $p<0.001$ except for muscular atrophy; Table 1 ). 
Table 1. Basic demographic and clinical characteristics of the control and patient groups

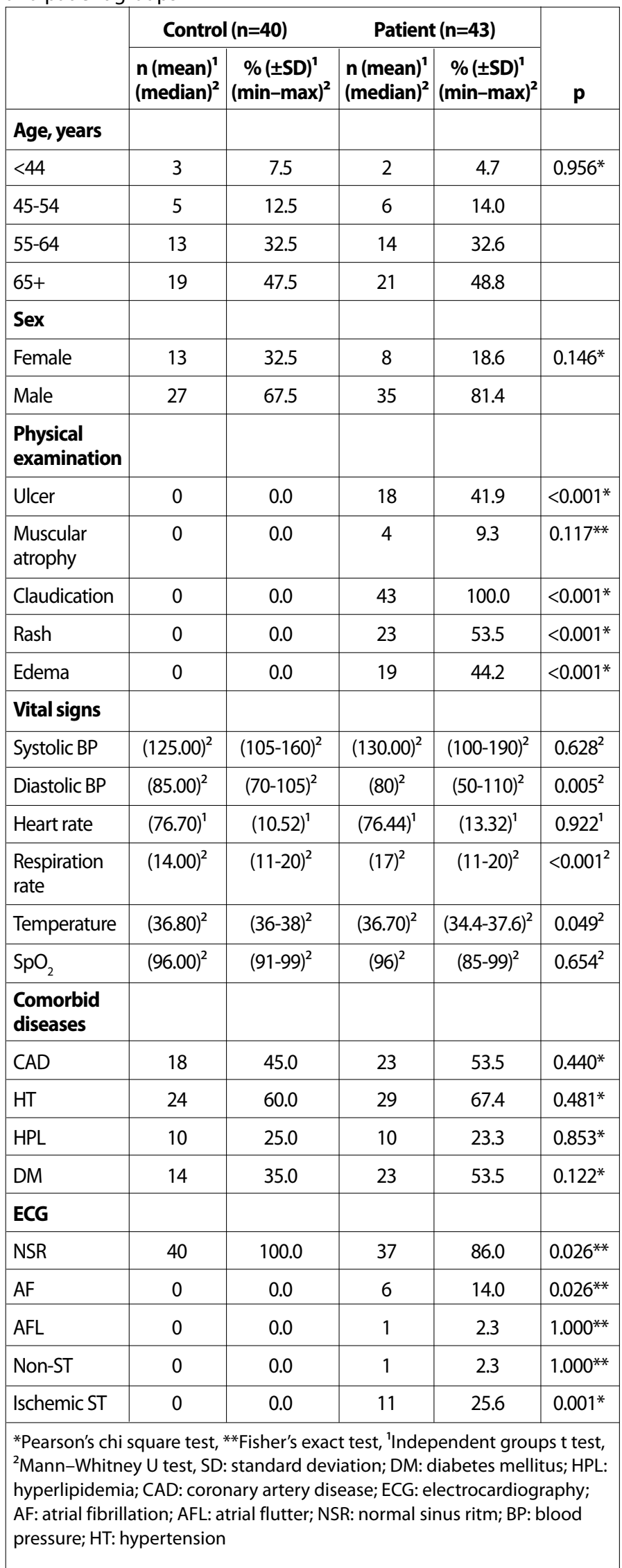

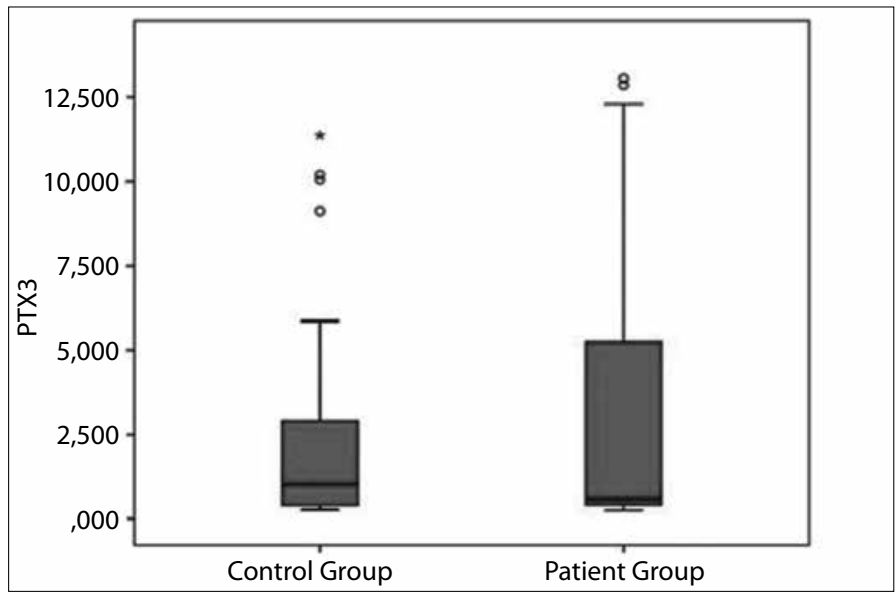

Figure 1. PTX3 values in the control and patient groups. PTX: pentraxin

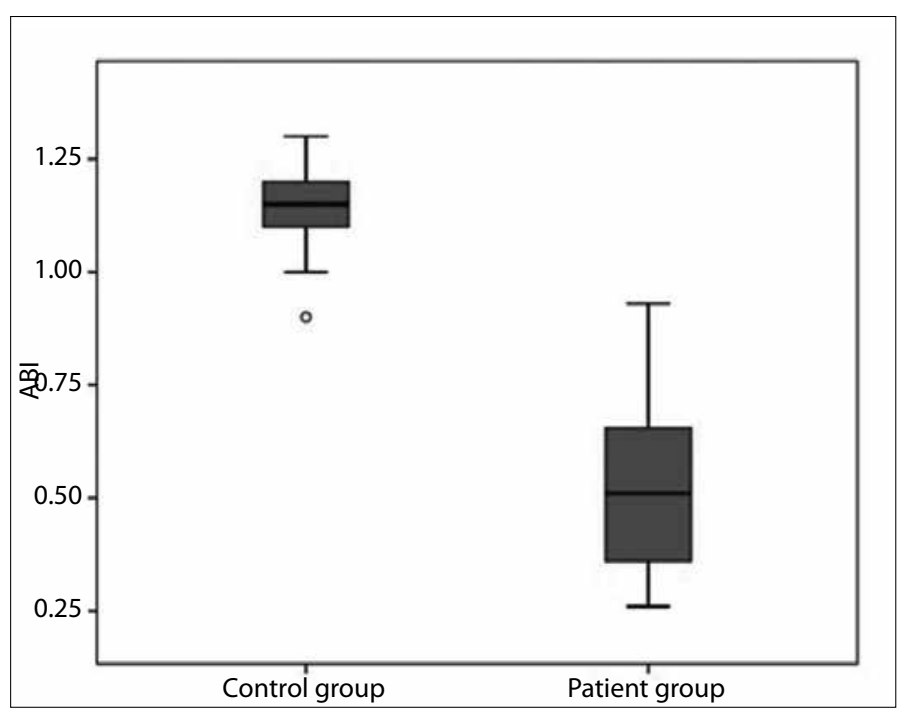

Figure 2. $A B I$ values in the control and patient groups. ABI: ankle brachial index

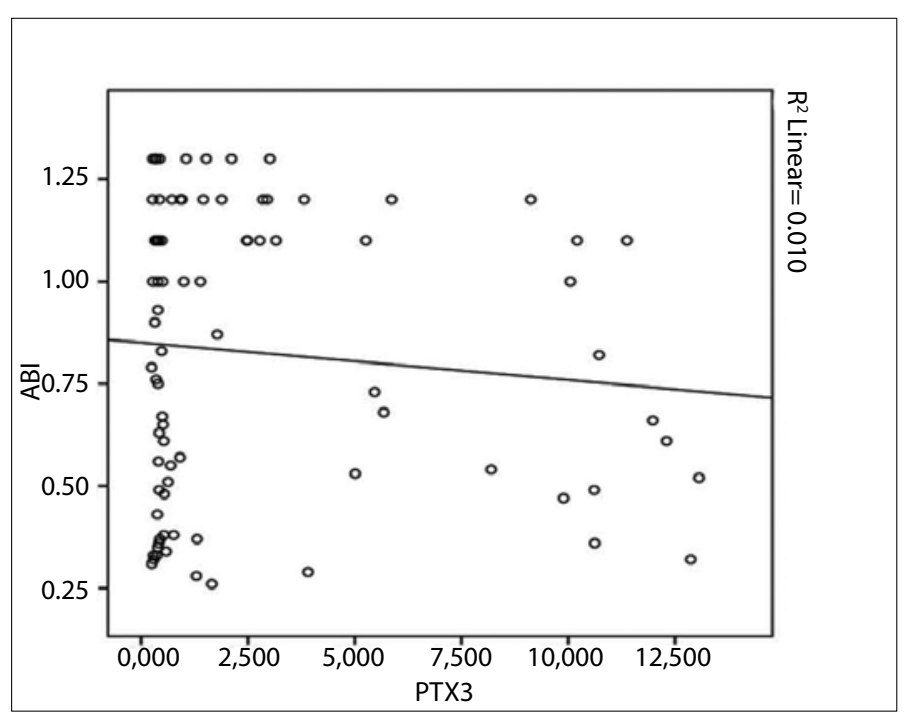

Figure 3. $\mathrm{PTX} 3$ and $\mathrm{ABI}$ correlation chart. PTX: pentraxin; $\mathrm{ABI}$ : ankle brachial index 
In terms of vital findings, mean diastolic blood pressure (BP) in the patient group $(77.58 \pm 12.55 \mathrm{mmHg})$ was significantly lower than that in the control group $(100.25 \pm 98.6 \mathrm{mmHg} ; \mathrm{p}=0.005)$. Similarly, in contrast, respiration rate was significantly higher in the patient group compared to the controls $(p<0.001$; Table 1$)$.

When patients were questioned about comorbidities other than PAD, coronary artery disease (CAD) was present in $45 \%$ of the control group and $53.5 \%$ of the patient group, hypertension (HT) in $60 \%$ of the control group and $67.4 \%$ of the patient group, hyperlipidemia (HPL) in $25 \%$ of the control group and $23.3 \%$ of the patient group, and diabetes mellitus (DM) in $35.0 \%$ of the control group and $53.5 \%$ of the patient group. No significant correlation was determined between the groups in terms of CAD, HT, HPL, or DM ( $p>0.05$; Table 1).

When participants' electrocardiography (ECG) findings were compared, normal ECG results were determined in almost all in the control group, while atrial fibrillation (AF) was determined in $14 \%$ of the patient group, atrial flutter (AFL) in $2.3 \%$, non-ST changes in $2.3 \%$, and ischemic ST elevation in $25.6 \%$ (Table 1 ).

Median PTX3 level in the control group was $1.027 \mathrm{ng} / \mathrm{mL}\left(25-75^{\text {th }}\right.$ percentile: $0.395-2.902)$, and $0.585 \mathrm{ng} / \mathrm{mL}$ (25-75 th percentile: 0.406 $5.467)$ in the patients with $\operatorname{PAD}(p=0.913$; Figure 1$)$. Median $A B I$ in the control group was 1.15 (25-75 th percentile: $1.10-1.20)$, significantly higher than the median value of patients with PAD at $0.51\left(25-75^{\text {th }}\right.$ percentile: 0.36-0.66; $p<0.001$; Figure 2).

A weak and insignificant correlation was observed when we compared $\mathrm{ABI}$ values currently used as a diagnostic test with the new method PTX3 ( $r=0.016 ; p=0.886$; Figure 3). PTX3 values investigated as a novel method also exhibited no significant correlation with any other measurement parameters (age, systolic BP, diastolic BP, heart rate, respiration rate, temperature, and $\left.\mathrm{SpO}_{2}\right)(\mathrm{p}>0.05)$.

Examination of the relations between PTX3 and sociodemographic variables, physical examination, and additional chronic diseases showed that none was a probable confounding factor. Accordingly, no correlation was determined between age, muscle atrophy, claudication, rash, edema, CAD, HT, HPL, DM, or smoking status and PTX3 values $(p>0.05)$.

\section{Discussion}

Mean PTX3 values were 1.027 ( $25-75^{\text {th }}$ percentile: $\left.0.395-2.902\right)$ in the control group and $0.585\left(25-75^{\text {th }}\right.$ percentile: $\left.0.406-5.467\right)$ in patients with PAD. The difference was not statistically significant $(p=0.913)$. Comparison of $\mathrm{ABI}$ values used as an existing diagnostic test and PTX3 revealed a weak and non-significant correlation ( $r=0.016 ; p=0.886)$. No significant association was observed with factors shown in the literature with PTX3 values.

Studies have reported varying prevalence of PAD. The prevalence of PAD in the general population aged over 40 years in Spain was reported as $9.7 \%$ in women and $11.4 \%$ in men (4). A prevalence level of $5 \%$ for PAD $(A B I<0.9)$ has been reported in individuals representing the general population aged $\geq 40$ years in the USA (5). A study conducted in a care home in Turkey involving 507 individuals aged $>60$ years reported a prevalence of PAD of $5.9 \%$, while a study that screened the general population aged $>40$ years reported a prevalence of $19.76 \%$ (6).

Various studies have been performed for the early identification of PAD (7). However, the application of PTX3, an inflammatory marker, in the diagnosis of PAD has not been previously investigated. As described, PTX3 plays an important role in the primary inflammatory response. It is therefore included among the diagnostic tests for several diseases and cardiovascular diseases (CVDs) in particular, from ovarian torsion to pleural fluid effusion and pulmonary contusion (8, 9). Immunohistochemical studies have shown that plasma PTX3 levels increase in atherosclerotic lesions but not in non-atherosclerotic lesions and have demonstrated that PTX3 is a marker of localized vascular inflammation. This has emphasized the importance of investigating the relation between clinical atherosclerotic events and PTX3 levels. Additionally, the determination of higher PTX3 levels in subjects with CVD compared to those without CVD among patients with myocardial infarction with systolic BP elevation has led to PTX3 levels also being investigated in this group (10). Zhou et al. (11) reported a negative, highly significant correlation between PTX3 and $A B I$ values. In our study, PTX3 and $A B I$ did not correlate to age, systolic $B P$, diastolic $B P$, heart rate, respiration rate, body temperature, or $\mathrm{SpO}_{2}$. Although Tomandlova et al. (10) referred to a significant correlation between age and PTX3, they reported no correlation between systolic or diastolic BP and PTX3, in agreement with our study. In a study investigating the relation between severity of PAD and endothelial progenitor cells (EPCs), Morishita et al. (12) reported that EPCs and PTX3 increased in a correlated manner in patients with PAD compared to those without PAD. In our study, and in contrast to Morishita et al. (12), PTX3 levels were lower in subjects with PAD, although the difference was not statistically significant. In addition, Morishita et al. (12) reported a $33.3 \%$ prevalence of DM, $71.4 \%$ of $\mathrm{HT}$, and $38.1 \%$ of CVD among subjects with PAD. In our study, the prevalence values in patients with PAD were $53.5 \%$ for DM, $67.4 \%$ for $\mathrm{HT}$, and $53.5 \%$ for CVD, indicating higher prevalence of DM and CVD but not HT. Additionally, mean systolic $(137.38 \pm 26.20 \mathrm{mmHg})$ and diastolic $(73.81 \pm 14.74 \mathrm{mmHg})$ BP values in the study by Morishita et al. (12) were similar to those of our study (systolic: 128.23 \pm 18.59 $\mathrm{mmHg}$; diastolic: $77.58 \pm 12.55 \mathrm{mmHg}$ ). Inoue et al. (13) compared mean plasma PTX3 levels by collecting blood specimens from 252 patients undergoing angiography for $C A D$ evaluation at a university hospital, with 162 patients under monitoring due to HT, HPL, DM, or CVD. Mean PTX-3 values of patients undergoing angiography with a preliminary diagnosis of ischemic heart disease were significantly high. In the study of patients with type 2 DM, Rashtchizadeh et al. (14) observed significantly higher mean PTX3 in patients with CAD compared to those with no CAD. However, no such relationship was observed in our study.

Studies regarding PTX3 have revealed that the levels of PTX3 also increase in some inflammatory diseases. In a study of patients with arthritis, Ishihara et al. (15) observed higher serum PTX3 levels in periods when the disease was active compared to when it was not active and compared to a healthy control group. They reported 
that PTX3 is more specific than C-reactive protein (CRP) in showing arterial inflammation. Fazzini et al. (3) investigated PTX3 levels in 43 patients with vasculitis. They observed higher PTX3 levels in active vasculitis compared to during times of no activation. Moreover, PTX3 levels when the disease was not activated and in the healthy control group was similar. The study also observed high PTX3 levels in an untreated vasculitis group and low levels in subjects receiving immunosuppressive therapy. They concluded that PTX3 may be a reliable acute phase reactant in showing inflammation in active vasculitis (3). Studies investigating risk factors for PAD have identified $\mathrm{DM}, \mathrm{HL}, \mathrm{HT}$, smoking, and obesity as such factors (16). More than $91 \%$ of patients with PAD were reported to have at least one risk factor for atherosclerosis (4). Similarly, in our study, $94 \%$ of patients had at least one such risk factor.

Several previously published studies have reported that coronary problems are encountered frequently in patients with PAD. In addition, one necroscopy study involving cases with lower extremity ischemia sufficiently severe to require amputation observed diffuse and severe coronary atherosclerotic and myocardial lesions in almost all these cases (17). CAD was diagnosed in 23 (53.5\%) of the PAD cases in this study. A history of non-ST elevation was present in 1 (2.3\%) patient and ischemic ST elevation in 11 (25.6\%). In addition, median value of $\mathrm{ABI}$ of 1.15 (25-75 th percentiles: $1.10-1.20)$ in the control group was significantly higher than median value of $A B I 0.51\left(25-75^{\text {th }}\right.$ percentiles: $0.36-0.66)$ in the subjects with PAD $(p<0.001)$, indicating that consistent results were obtained in the diagnosis of PAD.

\section{Study limitations}

The absence of any significant finding in this study despite PTX3 being closely associated with atherosclerosis and the fact that the result did not change despite the grading of confounding factors, show the need for a larger and randomized sample.

\section{Conclusion}

We consider that PTX3 levels remained unchanged in this study because despite its atherosclerotic foundation, PAD is a chronic process that does not develop acutely. Further studies with a larger patient group and with PAD classified according to subtypes are needed.

Ethics Committee Approval: Authors declared that the research was conducted according to the principles of the World Medical Association Declaration of Helsinki "Ethical Principles for Medical Research Involving Human Subjects", (amended in October 2013).

Informed Consent: Written informed consent was obtained from all participants who participated in this study.

Peer-review: Externally peer-reviewed.

Author Contributions: Concept - B.K.; Design - O.T.; Supervision - B.K.; Resources - B.K., A.A.; Materials - S.D.; Data Collection and/or Processing - U.M., B.K.; Analysis and/or Interpretation - A.M., A.O.; Literature Search - G.A., B.K.; Writing Manuscript - B.K., A.A.; Critical Review - O.T.
Conflict of Interest: The authors have no conflict of interest to declare.

Financial Disclosure: This study was supported by the Karadeniz Technical University Scientific Research Foundation (Project Number: TTU-2015-5358), Trabzon, Turkey.

\section{References}

1. Cecilia A. Gutierrez. Peripheral Arterial Disease. In: Paulman PM, Paulman AA, Harrison Taylor JD, editors.Taylor's Manual of Family Medicine. Philadelphia: Lippincott Williams \&Wilkins; 2008. p.339-43.

2. Van der Wal AC, Becker AE, Das PK. Medial thinning and atherosclerosis--evidence for involvement of a local inflammatory effect. Atherosclerosis. 1993; 103: 55-64. [CrossRef]

3. Fazzini F, Peri G, Doni A, Dell'Antonio G, Dal Cin E, Bozzolo E, et al. PTX3 in small-vessel vasculitides: an independent indicator of disease activity produced at sites of inflammation. Arthritis Rheum. 2001; 44: 2841-50. [CrossRef]

4. Carbayo JA, Divisón JA, Escribano J, López-Abril J, de Coca EL, Artigao $L M$, et al. Using ankle-brachial index to detect peripheral arterial disease: prevalence and associated risk factors in a random population sample. Nutr Metab Cardiovasc Dis. 2007; 17: 41-9. [CrossRef]

5. Menke A, Muntner P, Wildman RP, Dreisbach AW, Raggi P. Relation of borderline peripheral arterial disease to cardiovascular disease risk. Am J Cardiol. 2006; 98: 1226-30. [CrossRef]

6. Karabay $O$, Karacelik M, Yilik L, Tekin N, Iriz AB, Kumdereli S, et al. Ischemic peripheral arterial disease: A screening survey. Turk J Thoracic Cardiovasc Surg. 2012; 20: 450-7. [CrossRef]

7. Ambrosetti M. Timely diagnosis of lower extremity peripheral arterial disease: one of the many expected actions by the cardiologist. Int J Cardiol. 2014; 175: 217. [CrossRef]

8. Akman L, Erbas O, Terek MC, Aktug H,Taskiran D, Askar N. The long pentraxin-3 is a useful marker for diagnosis of ovarian torsion: An experimental rat model. J Obstet Gynaecol. 2016; 36: 399-402. [CrossRef]

9. Tatlı O, Keha Kurt N, Karaca Y, Sahin A, Aygun A, Sahin E, et al. The diagnostic value of serum pentraxin 3 levels in pulmonarycontusion. Am J Emerg Med. 2017; 35: 425-8. [CrossRef]

10. Tomandlova M, Jarkovsky J, Tomandl J, Kubkova L, Kala P, Littnerova S, et al. Prognostic value of pentraxin-3 level in patients with STEMI and its relationship with heart failure and markers of oxidative stress. Dis Markers. 2015; 2015: 159051. [CrossRef]

11. Zhou Y, Ni Z, Zhang J, Zhang W, Wu Q, Shen G, et al. Plasma pentraxin 3 may be a better marker of peripheral artery disease in hemodialysis patients than C-reactive protein. Vasc Med. 2013; 18: 85-91. [CrossRef]

12. Morishita T, Uzui H, Nakano A, Mitsuke $Y$, Geshi T, Ueda T, et al. Number of endothelial progenitor cells in peripheral artery disease as a marker of severity and association with pentraxin-3, malondialdehydemodified low-density lipoprotein and membrane type-1 matrix metalloproteinase. J Atheroscler Thromb. 2012; 19: 149-58. [CrossRef]

13. Inoue $K$, Sugiyama A, Reid PC, Ito $Y$, Miyauchi $K$, Mukai $S$, et al. Establishment of a high sensitivity plasma assay for human pentraxin3 as a marker for unstable angina pectoris. Arterioscler Thromb Vasc Biol. 2007; 27: 161-7. [CrossRef]

14. Rashtchizadeh N, Sede SA, Ghaffari MA, Mohammadzadeh G, Majidi $\mathrm{S}$. Associations of pentraxin 3 with presence and severity of coronary artery disease in type 2 diabetes patients. Turk J Biochemistry. 2015; 40: 37-43. [CrossRef]

15. Ishihara $T$, Haraguchi $G$, Kamiishi T, Tezuka D, Inagaki $H$, Isobe $M$. Sensitive assessment of activity of Takayasu's arteritis by pentraxin3, a new biomarker. J Am Coll Cardiol. 2011; 57: 1712-3. [CrossRef] 
16. Ankle Brachial Index Collaboration. Ankle brachial index combined with Framingham risk score to predict cardiovascular events and mortality. JAMA. 2008; 300: 197-208. [CrossRef]
17. Mautner GC, Mautner SL, Roberts WC. Amounts of coronary arterial narrowing by atherosclerotic plaque at necropsy in patients with lower extremity amputation. Am J Cardiol. 1992; 70: 1147-51. [CrossRef] 